\title{
Reflective Learning through Blog Reflections among TESL Undergraduates
}

Isolde Hon Pei Sha, Juridah Md Rashid, Jayakaran Mukundan, Nada Alkhatib

To Link this Article: http://dx.doi.org/10.6007/IJARBSS/v10-i12/8340

DOI:10.6007/IJARBSS/v10-i12/8340

Received: 05 November 2020, Revised: 30 November 2020, Accepted: 17 December 2020

Published Online: 29 December 2020

In-Text Citation: (Sha et al., 2020)

To Cite this Article: Sha, I. H. P., Rashid, J. M., Mukundan, J., \& Alkhatib, N. (2020). Reflective Learning through Blog Reflections among TESL Undergraduates. International Journal of Academic Research in Business and Social Sciences, 10(12), 462-476.

\section{Copyright: @ 2020 The Author(s)}

Published by Human Resource Management Academic Research Society (www.hrmars.com)

This article is published under the Creative Commons Attribution (CC BY 4.0) license. Anyone may reproduce, distribute, translate and create derivative works of this article (for both commercial and non-commercial purposes), subject to full attribution to the original publication and authors. The full terms of this license may be seen at: http://creativecommons.org/licences/by/4.0/legalcode

\section{Vol. 10, No. 12, 2020, Pg. 462 - 476}

Full Terms \& Conditions of access and use can be found at http://hrmars.com/index.php/pages/detail/publication-ethics 


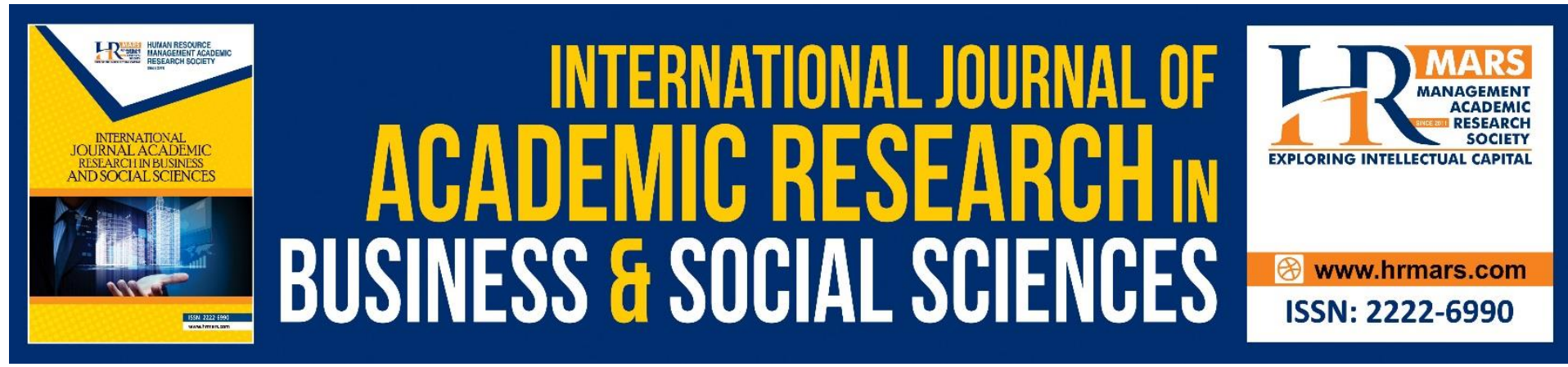

\title{
Reflective Learning through Blog Reflections among TESL Undergraduates
}

\author{
Isolde Hon Pei Sha, Juridah Md Rashid, Jayakaran Mukundan, \\ Nada Alkhatib
}

Faculty of Educational Studies, Universiti Putra Malaysia, 43400 UPM Serdang, Malaysia

Email: peisha1213@hotmail.com, juridahmr@upm.edu.my, jaya@upm.edu.my,

nalkhatib@iau.edu.sa

\begin{abstract}
Reflective learning $(R L)$, collaborative learning $(C L)$ and project-based learning (PBL) have long been acknowledged as important aspects of personal and professional development. The aim of this study was to identify the reflection dimensions (affective, behaviour and cognition) based on Sage's ABC-123 Table of Organizing Reflections and the writing stages that were embedded in the learners' blogs. The sampling for the study was purposeful and the participants were $10 \mathrm{TESL}$, 3rd year undergraduates. Research data was collected from participants' reflections through blog entries. In this study, data analysis also included the reading and transcription of blog entries. The findings of the study showed that participants were engaged in the reflection process and produced responses that included all three reflection dimensions within their personal and group blogs. More reflective writing was produced using the initial stages of reflection rather than those which required higher order thinking skills. This study expects to provide ESL instructors with valuable information on how students perceive and experience $\mathrm{RL}, \mathrm{CL}$ and $\mathrm{PBL}$ which are crucial to better equip our students holistically by integrating $\mathrm{RL}, \mathrm{CL}$ and $\mathrm{PBL}$ in their work to allow them to produce quality content even through an online setting.
\end{abstract}

Keywords: Blogs, Collaborative Learning, Project-Based Learning, Reflection, Reflective Learning.

\section{Introduction}

Weblogs or better known as blogs can be utilized for the purpose of reflecting on course work, assignments, careers, or even current events. Blogs can also be used to save and distribute content generated by the students and the faculty. RSS (Rich Site Summary) feeds allow access to blog content in various ways, such as newsreaders, providing the opportunity for bloggers to share information to individuals who are interested in the same field. Blogs offer a high level of autonomy and freedom in sharing information to students and the faculty, as well as other users from all around the world and at the same time, creating opportunities for peer interaction. Blogs provide a forum for extensive discussion that goes beyond coursework to other areas of personal exploration. Blogs also provide a medium that is efficacious for 
peer-to-peer knowledge sharing and application (Garrison \& Vaughan, 2008). Students are able to learn as much from their peers as from their teachers or textbooks.

Higher education institutions are beginning to look into the potential of blogs as a tool to help advocate meaningful learning and integration of learning experiences not just in the normal classroom setting but beyond it as well (Williams \& Jacobs, 2004). Blogs have the potential to promote collaborative or reflective learning by providing a medium for students to engage in reflection on resources and content (Dron, 2007; Williams \& Jacobs, 2004). On top of that, group blogs can be used for student-to-student communication and display of work. It is also a medium for the development of student portfolio, classroom management, reflective learning, as well as peer support (Hall \& Davidson, 2007).

Thus, it seems that blogging should have the potential to support reflective practice, which by right, should consequently connect the work done in the class with experiences the students have encountered in the outside world (Ahmadi et al., 2013; Beale, 2007; Li et al., 2018). Thus, a study is needed to discover the extent of RL and PBL's relevance in Malaysian classrooms and its impact on students. The study's specific intentions would require an indepth knowledge of students' interest and engagement with their blogs and projects, as well as their personal experiences in the process of completing the project. This study therefore, aims to explore the presence of reflective learning and collaborative learning in PBL and the interactions within reflective blogs of participants.

To some extent, educators in Malaysia are still comfortable with conventional classroom practices which no longer apply to our current classroom settings (Azarfam, et al., 2016; Jahedi \& Ismail, 2020). Such practices include the mind-numbing chalk-and-talk, tedious grammar drills and the overuse of school textbooks in classroom teaching. It is not uncommon claim, the subject matter used in school was boring and irrelevant to the real world outside of the classroom (Li et al., 2019; Waller, 1932). A study done by Keys and Fernandes (1993) had discovered that $9 \%$ of the students who participated in the study were experiencing boredom in all or most lessons, 55\% claimed they were bored with some lessons, while many students claimed their teachers rarely offer praises for their good work. About $40 \%$ of students indicated that during the year, they have yet to discuss their work with their teachers individually. Some think of the process of learning as dull and dreary, while some think of classroom life as boring, uninteresting, unimportant, or unsubstantial (Kennedy, 2005).

Decades later, a number of studies showed that teachers depended a lot on recitations that focused on insignificant facts and did not allow the students the opportunity to think about the content (Hoetker \& Ahlbrand, 1969). Currently, we can see that many teachers are still unaware of the fact that the teaching methods used in classrooms can no longer engage students. Thus, students find learning quite dull, unappealing and requires a lot of effort.

Ariffin and Yaacob (2014) found in their study that students generally agreed that blogs assisted them in improving the command of language by providing them a platform where everybody uses English as a medium to communicate. A study by Murugaiah and Thang (2010) showed that the exchange of knowledge and information with peers enhanced their drive to learn because learning from peers is less daunting compared to learning from teachers. Even though numerous studies have shown significant results in students' attitude and performance through the RL, CL and PBL approach, there has yet to be a study on RL with $\mathrm{CL}$ in PBL. Features of RL with $\mathrm{CL}$ in PBL will prove useful as it helps to identify the dimensions and characteristics of reflections that the students provide in the process of learning through these methods. This in turn would provide justification on the effectiveness of RL, CL and PBL. 
Therefore, this study was carried out to address the gaps in the research of RL, CL and PBL and provide the information needed on how learners relate to $\mathrm{RL}, \mathrm{CL}$ and $\mathrm{PBL}$ altogether.

In light of recent events (Covid 19 pandemic), a study such as this would prove useful as educators desperately need different approaches to help their students learn online. Since physical classes are no longer an option, online learning has become the only outlet for educators to impart knowledge in as many feasible ways as possible. As most educators struggle to engage in a more personal approach during an online interaction with students, $\mathrm{PBL}$ that incorporates $\mathrm{RL}$ and $\mathrm{CL}$ will be a great way to not only encourage students to cooperate online but also to gauge the students' inner thought processes in their attempt to complete an online assignment.

\section{Research Question}

What are the dimensions and frequency of reflections found in learners' blogs?

\section{Literature Review}

\section{Reflective Learning}

Reflection requires constant practice by attempting to grasp and relate historical, social and cultural, as well as personal experiences which lead to the development of professional knowledge and practice (Wilkinson, 1999). Moreover, Duffy (2007) believes that the practice of reflection requires the individual to actively and deliberately engage in the process of selfenquiry to realize what is necessary to achieve practice which is desirable and effective that leads to personal transformation.

In order to derive learning from experience, other than engaging in reflection, you must also acknowledge it by recording it. By immersing into our thoughts of the whats and whys of doing something, we are able to derive meaningful learning. As effective reflective practitioners, we will have to engage in reflective learning to develop professional knowledge and skills which will benefit us as learners. Reflections happen on a daily basis during quiet moments when we are by ourselves. As learners, reflective writing skills are necessary, although some may find it challenging, it is a skill that can be developed and improved with practice (Jasper, 2005).

\section{Reflective Learning through Blogs}

A blog is a website that is used as an online personal journal where the writers deliver their opinions, reflections, comments and even hyperlinks. Blogging is the gesture of writing one's thoughts and opinions within one's blog. The blogosphere is considered an intellectual cyberspace that bloggers inhabit. It has been reported that blogs proved to be a useful tool for language learners in accordance with the increasing popularity of online language teaching as well as the development of new multimedia literacy which help to foster collaborative and intercultural learning (Meskill \& Anthony, 2011; Guth \& Helm, 2010).

Little (1991) claimed that blogs are able to provide opportunities for students do develop learner autonomy which would later prove useful for detachment, critical reflection, decision-making and independent action. He further clarifies by stating that students will be able to take responsibility for ownership of their own writing as they independently produce publicly assessable documents.

Before blogs, hand-written journals were used as they provided similar opportunities for free, as a platform for unstructured writing practice for students. These journals were usually catered for students who have difficulties expressing themselves and are reluctant to 
speak. Other than providing the students with the opportunity to develop strategy awareness (Oxford 1996), they also develop metacognitive awareness (Palfreyman, 2005).

Yang, Chan, Lik-ko Ho, and Tam (2005) underlines the advantages of blogging that enhances interactive language learning, develops motivation in writing and promotes critical thinking and reflection skills. On top of that, language teachers can also use blogs to pose questions to students or to encourage them to express their opinions and concerns as well as strengthen the bond between student and teacher through enhanced interaction in the target language. This provides an opportunity for the teacher to conduct and facilitate peer reviews and self-assessment which would prove helpful for learners to practice reflection over the process and progress of learning. Yang et al. (2005) also claimed that students can establish a learning community through weblogs and select a topic of shared interest to write about collaboratively. This will enable them to read, and then comment on texts written by their colleagues participating in the same blog. As a result, this will motivate them to write more by participating in persistent discussions and reflections through a learner-centered environment.

Both Mynard (2007); Yang et al. (2005) emphasized the role of blogs in promoting reflective language learning and claimed that blogs can be viewed as a virtual classroom because blogs allow people from all over the world to share views, concerns and reflections about a topic of interest in the target language. It is said that through blogs, students are able to document their learning reflections every day and record important life experiences, and at the same time, share them with other people. Despite the fact that blogs are used in general education, research about the use of blogs in different contexts of language learning is still scarce.

Based on subjective analysis, it was suggested that the blogged entries were identified to be more evaluative and analytic as compared to handwritten journals from the previous semester of study. According to Stiler and Philleo (2003), longer entries were posted on students' blogs when compared to handwritten journals. The features of the entries showed that students were motivated to write more deliberately about their views rather than simply brushing off descriptions of what happened.

In a study done by Worthington et al. (2018), blogs were also used outside of the realm of pedagogy. The students used blogs to describe challenges the students faced on the project or to reflect on how knowledge they developed from the project could be applied in their lives. A few students also used blogs to set personal learning goals and others described their goals of developing creative and useful resources.

Blog reflections enable students to be aware of their learning through a metacognitive process. It is said that essential questions and visible thinking routines support critical thinking in the students' thought process and enables them to create a more powerful model for digital portfolios. As students' learning remain the central focus, through their reflections on each experience, they become more aware of the processes and strategies that make them successful, enabling them to learn from their successes, challenges or failures (Holland, 2015).

Davis (2015) explained that blogging provides an avenue for students to publish not just to the instructor, but to a wider audience as well. This includes everything (multimedia) from text, images, videos and audio records. When students openly share their work to the public, it allows for a different sense of engagement. In a typical classroom, discussions are usually restricted to the available audience, the blog allows the students to broaden their conversation perspective with authentic audiences from around the world. 
With the increasing need for online learning strategies and insufficient studies on project-based learning reflections, it is necessary to carry out a study that identifies the TESL students' reflection on their output through a digital platform such as blogs. Since there were many past researches done on the use of blogs, this study will prove relevant as it is now the best time to apply blogging as part of our teaching and learning strategy in online classrooms during this unprecedented pandemic. From this study, we will not only be able to identify the student's perception of the project but also to better understand their refined thought processes in both their individual and collaborative work, as well as how they improve their English language.

\section{Methods}

\section{Research Design}

This research employed qualitative content analysis which is commonly used in search of the underlying themes in the materials used for analysis (Bryman, 2004). He also defined qualitative content analysis as an approach that focuses on the role of the investigator in the establishment of the meaning in texts. In this design, significant serendipitous findings were also acknowledged within the context of the on-going analysis.

The three primary data sources in this study were videos, blogs and people. 'Videos' is referred to the video projects and the storyboards that the participants of this study have developed-and this included the first draft and the revised version. 'Blogs' is referred to their individual blogs where they have posted their thoughts, feelings and ideas online. 'People' is referred to the learners (B.Ed. TESL students of UPM) and this included their language experiences, interpretations, memories, thoughts, ideas, opinions, emotions and perceptions in relation to their video project and blogs.

\section{Sample}

The study employed a purposive sampling technique where the samples are only limited to those from the aforementioned batch of 3rd Year B. Ed. TESL students who were directly involved with the assigned video project that year. The researchers were able to achieve a final list of 10 participants from the cohort, with 2 participants from each of the 5 groups involved in the video project. This was a number that the researchers were comfortable with and felt that they were able to achieve the required findings within the constraints of time and accessibility. Thus, these samples may not represent the voice of the students in general, making this a case study of a specific population. The researchers adopted the illustrative case study which is descriptive in nature. It is designed to highlight a particular situation, set of circumstances, and the social relations and processes which are related to them.

From the qualitative point of view, the gathering of 'in-depth' knowledge, information and perceptions was often obtained using inductive and qualitative methods such as discussions, interviews and observations of the research participants (Mason \& Pauleen, 2003). This study used qualitative interview and content analysis on reflective blogs as well as video productions to gather the data that was needed.

\section{Procedure}

In this study, the participants used Blogger (a weblog) as their main blogging sites throughout the entire process of working on the video project, from the pre-writing stage up to postpublication. Participants were asked to administer one individual blog for each participant and one group blog for every group. They were also asked to post blog entries at least once a 
week or every time there is a turn of events within their group projects. They were encouraged to write about their thoughts, feelings and perceptions of their own work and also comment on the work of other individuals or groups.

The participants were asked to produce a 3-minute video that conveys issues pertaining to young adults. This video-project was part of a course requirement of LHE 4210 (Teaching of Writing Skills). Participants worked in groups (5-6 people) to produce the final product in the course of 4 weeks (a review on the first draft will be done during the 2 nd week) and were required to blog about their experience working on the video project. The participants had both a group blog and an individual blog. The group blog was for the group to express their expectations, feelings and reflections of their video project as a unit, while the individual or personal blog was for them to express their thoughts, feelings and reflections as individuals. Participants were required to post about their video project at least once per week, about their progress and their opinions about it. Weekly posts were made compulsory to ensure the continuous engagement of the participants and to consistently identify their progress and change as they move forward in the video project.

The researchers had arranged an agreeable time to meet the chosen participants to first and foremost explain the objectives of the research, brief them on what was expected from the study and also to gain the consent of each participant to agree to the participation in the study. Background information was obtained from the participants during the briefing as well.

All participants were advised to post blog entries every week, possibly after every meet-up session with their group members or after every physical progress they have made for their video project. This was to ensure the blog entries were relevant to their feelings and thoughts of the moment as much as possible. This was also to prevent the loss of data due to the time gap between the video processing and the writing of their blog entries.

A semi-structured interview was constructed and conducted to interview each participant. Open-ended questions were also constructed and arranged in coherent order to obtain the required information to answer the research questions of the study. All interviews were recorded and transcribed. The interview transcriptions were given back to the participants for verification. This was to confirm and establish a relevant link between the interview and their reflective blog entries. For some participants, online interviews were carried out via Synchronous Communication in which participants responded through instant messaging app or chat, text message, voice-over internet protocol, and videoconferencing or video call (Salmons, 2011).

Considering the availability of affective, behavioral and cognitive reflections in participants' blog entries, the researchers have adopted the ABC-123 Method to organize the dimensions of reflections developed by Sage (2007) who in turn credited Welch (1999) for pioneering the method in Table 1. 
Table 1

ABC-123 Table of Organizing Reflections (Sage, 2007)

\begin{tabular}{|c|c|c|c|}
\hline $\begin{array}{l}\text { Dimensions of } \\
\text { Reflection: }\end{array}$ & $\begin{array}{c}1 \text { - personal } \\
\text { level }\end{array}$ & $\begin{array}{c}2 \text { - "other" } \\
\text { level }\end{array}$ & $\begin{array}{l}3 \text { - social } \\
\text { level }\end{array}$ \\
\hline $\begin{array}{l}\text { A - Affective, } \\
\text { feelings }\end{array}$ & $\begin{array}{l}\text { This is how I felt. } \\
\text { This is how I feel now. }\end{array}$ & $\begin{array}{l}\text { This is how he feels. } \\
\text { This is how she felt. }\end{array}$ & $\begin{array}{l}\text { These feelings seem to } \\
\text { be shared by society at } \\
\text { large. }\end{array}$ \\
\hline $\begin{array}{r}\text { B - Behaviour, } \\
\text { actions }\end{array}$ & $\begin{array}{l}\text { This is what I did. This } \\
\text { is what I will do. }\end{array}$ & $\begin{array}{l}\text { This is what other } \\
\text { people are doing or } \\
\text { have done. }\end{array}$ & $\begin{array}{l}\text { This is what society is } \\
\text { doing, has done, or } \\
\text { should do. }\end{array}$ \\
\hline $\begin{array}{r}\mathrm{C}-\text { Cognition, } \\
\text { thinking }\end{array}$ & $\begin{array}{l}\text { This is what I } \\
\text { thought. This is what } \\
\text { I think now. }\end{array}$ & $\begin{array}{l}\text { This is what others } \\
\text { thought, what they } \\
\text { now think, or what } \\
\text { they should think. }\end{array}$ & $\begin{array}{l}\text { This is what society } \\
\text { thinks as indicated } \\
\text { by...<the legal \& } \\
\text { political system, } \\
\text { etc.> }\end{array}$ \\
\hline
\end{tabular}

In this study, codes were used to distinguish the different dimensions of reflections based on the table above in Table 2:

Table 2

ABC-123 Dimension Code

\begin{tabular}{cccc}
\hline Dimensions & Personal & Other & Social \\
\hline Affective & A1 (Affective/Personal) & A2 (Affective/Other) & A3 (Affective/Social) \\
Behaviour & B1 (Behaviour/Personal) & B2 (Behaviour/Other) & B3 (Behaviour/Social) \\
Cognition & C1 (Cognition/Personal) & C2 (Cognition/Other) & C3 (Cognition/Social) \\
\hline
\end{tabular}

\section{Results}

The findings indicating the different reflection dimensions as perceived by the participants in their blog entries are reported in the following sections according to the different stages in writing and in random order of the participants.

\section{The Frequency of Reflection Dimensions (Affective, Behaviour \& Cognition)}

The table below (Table 3 ) shows the tabulation of the different dimensions of reflections found in the individual and group reflective blogs.

In this study, A1 (Affective/Personal) refers to the affective response of a participant towards oneself. This involves the participants' personal feelings about their undertakings in the project. A2 (Affective/Other) is the feelings of others that the participant is aware of, while A3 (Affective/Social) is an affective response which the participants think everyone/all group members/the society at large share mutual feelings about matters concerning the video project. 
As for B1 (Behaviour/Personal), this response indicates the participants' personal behavior in the project. Participants either write about what they did or what they plan to do in the project. B2 (Behaviour/Other) are the actions of others that the participants reflected on, whether it is what they have done or what they plan to execute while working on the project. B3 (Behaviour/Social) involves the participants' responses about what everyone has done, is doing or should do to complete the given task in this project.

On the other hand, C1 (Cognition/Personal) responses describe the participants' personal thoughts about themselves, about other people or about matters concerning the project. C2 (Cognition/Other) responses describe participants' reflections on the thoughts of other people such as their teammates, other group members or even the reviewers of their videos. In addition, C3 (Cognition/Social) responses are those that participants wrote based on what everyone involved in the project or the society thought in general about matters pertaining the video project.

The reflections of the participants were read through and sorted out into the different reflection dimensions based on the criteria of each dimension mentioned in the section above. In this study, participants were assigned pseudonyms in order to protect their identity. This is in accordance with the reassurance of anonymity that had been outlined to them as ethical considerations in this study. The pseudonyms assigned in Table 3 are English names in replacement of their real names which protects their true identity.

Table 3

Frequency of Reflection Dimensions

\begin{tabular}{cccccccccc}
\hline & \multicolumn{7}{c}{ Reflection Dimensions } \\
\cline { 2 - 9 } Natalie & 1 & - & - & - & - & 2 & 1 & - & 2 \\
Renee & 2 & 1 & - & 2 & 2 & - & 3 & - & 2 \\
Wendy & 2 & - & 1 & - & - & 2 & 3 & - & - \\
Tina & 1 & - & 1 & 1 & - & 1 & 1 & - & - \\
Helen & 1 & - & - & - & 2 & 1 & 2 & 2 & 3 \\
Peggy & 1 & - & 1 & - & 1 & 3 & 2 & - & 2 \\
Fiona & - & - & - & - & 1 & 2 & 2 & 1 & 2 \\
Mary & 1 & - & 1 & 1 & - & 1 & 2 & - & - \\
Adam & 1 & - & - & 1 & - & 1 & 3 & 1 & 1 \\
Zachary & 2 & 1 & - & - & - & 4 & - & - & 1 \\
Total & $\mathbf{1 2}$ & $\mathbf{2}$ & $\mathbf{4}$ & $\mathbf{5}$ & $\mathbf{6}$ & $\mathbf{1 7}$ & $\mathbf{1 9}$ & $\mathbf{4}$ & $\mathbf{1 3}$ \\
\hline
\end{tabular}

Table 3 shows the frequency of reflections according to different reflection dimensions. The highest frequency is recorded by the reflection in dimension $\mathrm{C} 1$ with 19 responses. Coming up close to $\mathrm{C} 1$ is dimension $\mathrm{B} 3$ with 17 responses, followed by $\mathrm{C} 3$ with 13 responses, $\mathrm{A} 1$ with 
12 responses, B2 with 6 responses, B1 with 5 responses, A3 and $C 2$ both with 4 responses and the lowest frequency is dimension $A 2$ with only 2 responses.

Figure 1 shows that there is a total amount of 12 responses for $A 1,2$ responses for $A 2,4$ responses for $A 3,5$ responses for $B 1,6$ responses for $B 2,17$ responses for $B 3,19$ responses for $\mathrm{C} 1,4$ responses for $\mathrm{C} 2$ and 13 responses for $\mathrm{C} 3$. These results indicate that students are more inclined to provide reflections of their own feelings as individuals, what they do as a collective group, their thoughts as individuals and their thoughts as a collective group.

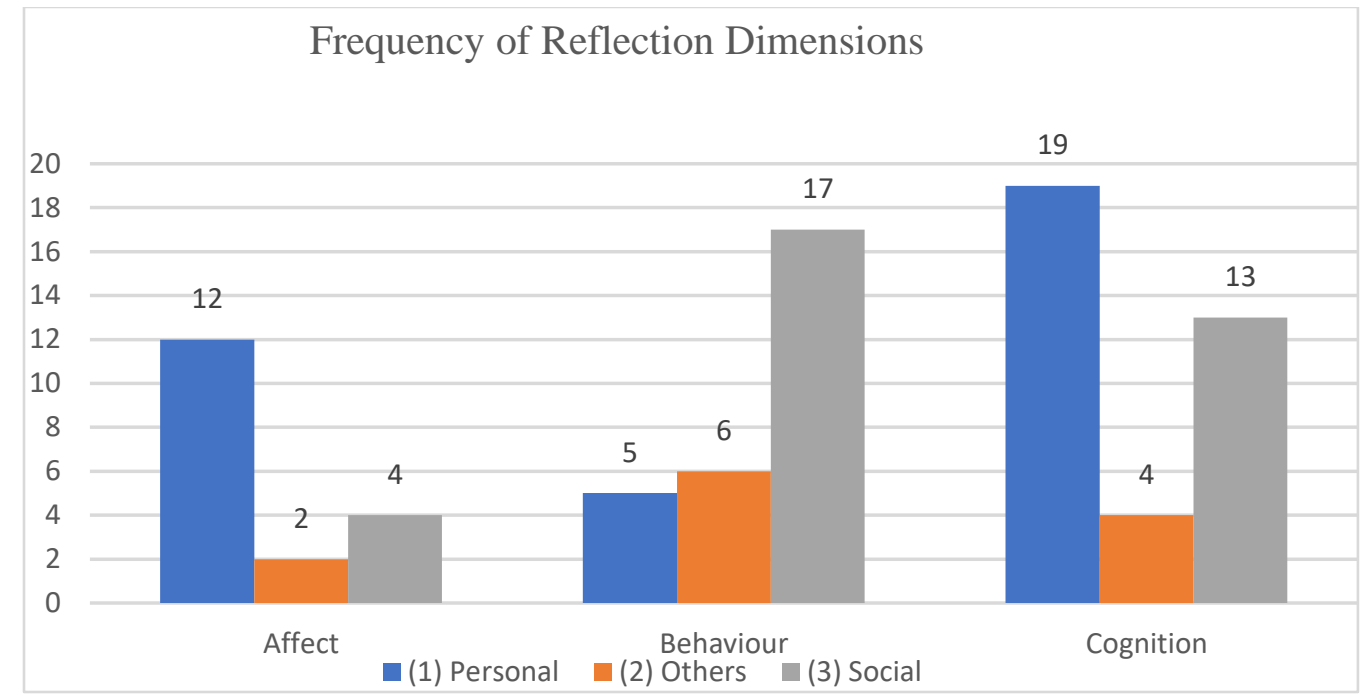

Figure 1. Frequency of Reflection Dimensions

\section{The 5 Basic Stages of Writing}

After looking through the participants' blog entries, the researchers have decided that the responses under different dimensions can also be categorized into 5 basic stages of writing: Prewriting, drafting, revising, editing and publishing.

In this study, the stages of writing were observed as the process in which the participants attempt to complete the video project. Prewriting is the first stage of the writing process. It usually involves the initial planning of writing such as researching on the given theme or topic, listing out ideas and mind-mapping. Drafting refers to the stage when writing is done on paper in paragraph form. The paragraphs usually include a thesis statement, topic sentences and sentence support which have coherence and unity. In this study, drafting refers to the process of story-boarding, where participants draft their ideas on a simple story-board as a guide prior to filming the video. As for revising, a great deal can change within this stage. Participants add, rearrange, remove or replace information to make their writing or stories better. Revising happens after constructive comments were given by the lecturer and peers. Participants take down notes and attempt to make changes to improve video quality and clarity. Furthermore, editing involves checking for errors such as repetition, grammar, coherence and clarity. Here, participants make final changes to their video and cross-checks with their group members and their peers to make sure that they have executed what they have planned. Finally, publishing involves the publication of the videos and presenting it to the whole class where the final evaluation takes place. These 5 basic stages of writing highlight the participants' train of thoughts in the process of producing content for their blogs. Here we can see the approaches engaged by the participants in organizing their ideas for both the video project and the blog posts. 
The blog posts were collected, read-through and validated by an expert (a lecturer who is familiar with this field of study) as to which stage these particular reflections belong to.

Table 4 below shows the number of responses recorded in each writing stage in accordance with 3 different reflection dimensions (affective, behavior and cognition) mentioned in the previous section.

Table 4

Frequency of Writing Stages in accordance with Reflection Dimensions

\begin{tabular}{ccccc}
\hline $\begin{array}{c}\text { Writing } \\
\text { Stages }\end{array}$ & Affective & $\begin{array}{c}\text { Reflection Dimensions } \\
\text { Behaviour }\end{array}$ & Cognition & Total \\
\hline Prewriting & 4 & 6 & 3 & 13 \\
Drafting & 4 & 9 & 9 & 22 \\
Revising & 4 & 4 & 8 & 16 \\
Editing & 1 & 5 & 10 & 16 \\
Publishing & 5 & 3 & 7 & 15 \\
Total & 18 & 27 & 37 & 82 \\
\hline
\end{tabular}

Table 4 shows data collected from participants' blog entries and the tabulation of responses according to 5 writing stages and 3 reflection dimensions. According to the data collected, the stage of drafting scores the highest with 22 responses out of 82 responses collected for this section of the study. The revising and editing stage recorded 16 responses each, followed by publishing with 15 responses and finally prewriting with 13 responses. Here, it is evident that the dimension with the least responses is the affective dimension with 18 responses, followed by the behavior dimension with 27 responses. The cognition dimension scored the highest with a total of 37 responses.

\section{Discussions}

From the data collected above, it can be inferred that C1 (Cognition/Personal) scored the highest frequency among all the other reflection dimensions with a total score of 19 responses. This score is followed by B3 (Behaviour/Social) with 17 responses, C3 (Cognition/Social) with 13 responses and A1 (Affective/Personal) with a number of 12 responses.

With C1 (Cognition/Personal) scoring the highest among the rest, this indicates that participants are more inclined to reflect on their own thoughts concerning the given task. It is only natural that one has more insights to one's own thoughts. Surbeck et al. (1991) identified the first level of reflection as reacting - commenting towards the learning experience, by reacting with personal concern about an event. Blogging about what they were thinking about before, during and after executing their plans is a practical task for most participants. Since, thinking is an inescapable part of idea generation, personal metacognition of each participant was easily penned down in their blogs. 
Both B3 (Behaviour/Social) and C3 (Cognition/Social) dimensions also showed a high score of 17 and 13 responses respectively. This indicates that reflecting on collective thoughts and behaviour is also a trend in the reflections of this video project. As introduced by RoffeyBarentsen and Malthouse (2009) the dialogic reflection level is identified as descriptions of their own experiences and the inclusion of the possible reasons for why things happened and how they contributed to the event. Since this is a group project, participants were able to personally observe and manage their team work throughout the process of completing the project. In these dimensions, participants blogged about how ideas were formed in the initial stages of the project, what decisions they have made and how they have solved problems as a group.

Likewise, A1 (Affective/Personal) achieved a high score of 12 responses. Participants are also inclined to blog about their feelings concerning the video project. Some blogged about their reactions towards the videos of other publishers, some expressed about their past experiences with video projects and how they felt about it, a handful blogged about their feelings towards their own achievements in the project, while the rest blogged about what they felt about their own teammates, other team members and even the lecturer's review. Carroll (2010) mentioned that at a certain level of reflection, the reflector becomes more observant with the acknowledgement of feelings.

Both A3 (Affective/Social) and C2 (Cognition/Other) scored the lowest at 4 responses. The former reflection is less popular since individuals rarely share the same feelings in every aspect of the video making process. Thus, it is difficult for participants to blog about a mutual feeling that everyone shares at a certain moment in time. Plus, feelings are not always an outward expression. Individual feelings are only comprehensible if they are expressed and shared with the rest of the group members, otherwise no one will know. As for the latter, individuals view themselves more vividly than others. Thus, like the former, the thoughts of others are not always clear unless the others make a point to clarify what they were thinking about to the rest of the group. Roffey-Barentsen and Malthouse (2009), claimed that critical reflection demands a higher-level metacognition skill as it requires the reflector to assume a more evaluative position where the event is examined from a range of perspectives or viewpoints which are then utilized to enable better comprehension of what happened and why it happened.

A1, C1, B3 and C3 are deemed to be more popular because individuals were able to have better observation of their own actions and actions taken as a group compared to other individuals in isolation. Individuals have tendencies to share more about their own views because most students' reflections are at the stage of self-reflection and self-awareness (Yaffe, 2010) as it is clearer and more comprehensible from their own perspectives as compared to $\mathrm{A} 3$ and $\mathrm{C} 2$.

In this study, the researchers have collected and categorized the participants' responses into 3 dimensions of reflections as suggested by Sage (2007), namely the affective, behavioural and cognitive dimensions. The findings showed that the dimensions of $A 1, C 1, B 3$ and C3 were more popular because individuals developed more insights of their own selves compared to others. Participants preferred to share more about their own views because it is more vivid and more comprehensible from their own perspectives as compared to A3 and C2. Describing what they know is usually the first step taken in any introductory presentation. As explained in Bloom's Taxonomy (Bloom, 1956), the cognitive domain comes first and the first level within the domain is knowledge. The knowledge level involves recalling, defining and describing data or information. Thus, we can see that participants are inclined to share 
more personal views because they were able to recall what they have experienced at first hand and provide justification for their own disclosure.

\section{Conclusions}

In this paper, the researchers had collected and categorized the participants' responses into 3 dimensions of reflections as suggested by Sage (2007), namely the affective, behavioural and cognitive dimensions. The findings showed that the dimensions of A1, C1, B3 and C3 are more popular because individuals developed more insights of their own selves compared to others. Participants prefer to share more about their own views because it is more vivid and more comprehensible from their own perspectives as compared to A3 and C2. Describing what they know is usually the first step taken in any introductory presentation. As explained in Bloom's Taxonomy (Bloom, 1956; Darwish \& Abdeldayem, 2019), the cognitive domain comes first and the first level within the domain is knowledge. The knowledge level involves recalling, defining and describing data or information. Thus, we can see that participants are inclined to share more personal views because they were able to recall what they have experience at first hand and provide justification for their own disclosure.

Regardless, all the reflection dimensions presented in this study are crucial in indicating the engagement of students in the reflections of themselves as well as others. It is necessary to reflect on private issues and share each other's personal experiences. This way, learners will find more connections with other people as well as a sense of safety and belonging to a collective group. Moreover, this process also provides each learner with the social support they require. As for collective reflection, the interpretation of what was done and why it was done were identified by involving themselves and others in conversations, debates, and reflections on individuals and collective understandings. This as a result, helps learners to better understand themselves and others, in order to identify strengths and potential within individuals and collective groups in an assigned project. The activity of blogging could be an efficient and effective alternative to online learning for ESL learners since there is a need for more features of $R L, C L$ and $P B L$ beyond the classroom setting. This is especially useful during the Movement Control Order (MCO) of this Covid 19 pandemic, where teaching and learning are limited to a virtual platform. This study provides an alternative for ESL language instructors to reach out to their students by exploring all available and potential online platforms such as blogging. By employing its features and revamping their teaching and learning strategies, instructors will have the capacity of making it equally as productive as a face-to-face classroom in spite of this pandemic.

\section{Acknowledgments}

I like to say my regards to Faculty of Educational Studies-UPM in having the opportunity and facilities during this research.

\section{References}

Ahmadi, P., Samad, A. A., \& Noordin, N. (2013). Identity formation of TEFL graduate students through oral discourse socialization. Theory and Practice in Language Studies, 3(10), 1764-1769. doi: 10.4304/tpls.3.10.1764-1769

Ariffin, Z., \& Yaacob, A. (2014). BALL (Blogs Assisted Language Learning): Are Malaysian Secondary School students pepared to use blogs in ESL learning?. Advances in Language and Literary Studies, 5(5), 123-132. doi:10.7575/aiac.alls.v.5n.5p.123 
Azarfam, A. Y., Samad, A. A., \& Noordin, N. (2016). Exploring EFL learners' attitudes toward the application of a model of writing e-portfolio. International Journal of Applied Linguistics and English Literature, 5(3), 57-68. doi:10.7575/aiac.ijalel.v.5n.3p.57

Beale, R. (2007). Blogs, reflective practice and student-centered learning. [Paper presention]. Proceedings of $\mathrm{HCl} 2007$ The 21st British $\mathrm{HCl}$ Group Annual Conference University of Lancaster, UK $(\mathrm{HCl})$. Lancaster, United Kingdom. https://doi.org/10.14236/ewic/hci2007.47

Bloom, B. S. (1956) Taxonomy of educational objectives, handbook: The cognitive domain. : New York: Addison-Wesley Longman

Bryman, D. M. A. (2004). Qualitative research on leadership: A critical but appreciative review. The Leadership Quarterly, 15(6), 729-769. doi:10.1016/j.leaqua.2004.09.007

Carroll, M. (2010). Levels of reflection: On learning reflection. Psychotherapy in Australia, 16(2), 24-31.

Darwish, S., \& Abdeldayem, M. M. (2019). Risk Management and Business Ethics: Relations and Impacts in the GCC. International Journal of Civil Engineering and Technology, 10(10), 489-504.

Dron, J. (2007). Designing the undesignable: Social software and control. Educational Technology \& Society, 10(3), 60-71.

Davis, A. (2015). Blogging in the classroom - A reflection. Readwriterespond.com https://readwriterespond.com/2015/08/blogging-in-the-classroom-a-reflection/

Garrison, D. R., \& Vaughan, N. D. (2008). Blended learning in higher education: Framework, principles, and guidelines. Wiley.

Guth, S., \& Helm, F. (2010). Telecollaboration 2.0: Language, literacies and intercultural learning in the 21st century. PeterLang.

Hall, H., \& Davison, B. (2007): Social software as support in hybrid learning environments: The value of the blog as a tool for reflective learning and peer support. Journal of Library and Information Science Research, 29(2), 163-187. doi:10.1016/j.lisr.2007.04.007

Hoetker, J., \& Ahlbrand, W. P. (1969). The persistence of the recitation. American Educational Research Journal, 6(2), 145-167. doi:10.3102/00028312006002145

Holland, B. (2015, June 30). The art of reflection. Edutopia. https://www.edutopia.org/blog/digital-portfolios-art-of-reflection-beth-holland

Jahedi, M., \& Ismail, L. (2020). Factors affecting ESL students' willingness to communicate in English classroom discussions and their use of linguistic strategies. Universal Journal of Educational Research, 8(8), 3360-3370. doi:10.13189/ujer.2020.080808

Jasper, M. A. (2005). Using reflective writing within research. Journal of Research in Nursing, 10(3), 247-260. doi:10.1177/174498710501000303

Kennedy, C. A. (2005). The BEAR assessment system: A brief summary for the classroom Context. Berkeley Evaluation \& Assessment Research Center.

Keys, W., \& Fernandes, C. (1993). What do students think about school?. In Moon, B. \& Mayes, A. S. (Ed.), Teaching and learning in the secondary school (pp. 94-100). Routledge.

Li, K. L., Razali, A. B., \& Baki, R. (2019). Writing narrative essays using e-book writing software: Analyses of students' digital written works. Journal of Asia TEFL, 16(4), 1289-1304. doi:10.18823/asiatefl.2019.16.4.14.1289

Li, K. L., Razali, A. B., Noordin, N., \& Samad, A. A. (2018). The role of digital technologies in facilitating the learning of ESL writing among TESL pre-service teachers in Malaysia: $A$ review of the literature. Journal of Asia TEFL, 15(4), 1139-1145. doi:10.18823/asiatefl.2018.15.4.18.1139 
Little, D. (1991). Learner autonomy 1: Definition, issues and problems. Dublin: Authentik. Mason, D., \& Pauleen, D. J. (2003). Perceptions of knowledge management: A qualitative analysis. Journal of Knowledge Management, $7(4), \quad 38-48$. doi:10.1108/13673270310492930

Meskill, C., \& Anthony, N. (2011). Review of telecollaborative 2.0: Language literacies and intercultural learning in the 21st century. Language Learning \& Technology, 15(1), 2123.

Murugaiah, P., \& Thang, S. M. (2010). Development of interactive and reflective learning among Malaysian online distant learners: An ESL instructor's experience. The International Review of Research in Open and Distributed Learning, 11(3), 21-41. doi:10.19173/irrodl.v11i3.842

Mynard, J. (2007). A blog as a tool for reflection for English language learners. The Philippine ESL Journal, 1(1), 77-89.

Palfreyman, D. (2005). Othering in an English language program. TESOL Quarterly, 39(2), 211233. doi:10.2307/3588309

Roffey-Barentsen, J., \& Malthouse, R. (2009) Reflective practice in the lifelong learning sector. Learning Matters Ltd.

Sage, J. (2007). Effective assessment and reflection. [Paper presentation]. Break-out Session at the Service-Learning Teaching Colloquium. Stevens Point, Wisconsin.

Salmons, J. (2011). Cases in online interview research. SAGE Publications.

Stiler, G. M., \& Philleo, T. (2003). Blogging and blogspots: An alternative format for encouraging reflective practice among preservice teachers. Education, 123(4), 789-797.

Surbeck, E., Han, E. P., \& Moyer, J. (1991). Assessing reflective responses in journals. Educational Leadership, 48(6), 25-27.

Waller, W. (1932). The sociology of teaching. John Wiley \& Sons, Inc.

Welch, M. (1999). The ABCs of reflection: A template for students and instructors to implement written reflection in service-learning. NSEE Quarterly, 25(2), 123-25.

Wilkinson, J. (1999). Implementing reflective practice. Nursing Standard, 13(21), 36-40.

Williams, J. B., \& Jacobs, J. S. (2004). Exploring the use of blogs as learning spaces in the higher education sector. Australasian Journal of Educational Technology, 20(2), 232-247. doi:10.14742/ajet.1361

Worthington, P., Reniers, J., Lackeyram, D., \& Dawson, J. (2018). Using a project blog to promote student learning and reflection. Canadian Journal of Higher Education, 48(3), 125-140. doi:10.7202/1057132ar

Yaffe, E. (2010). The reflective beginner: Using theory and practice to facilitate reflection among newly qualified teachers. Reflective Practice, 11(3), 381-391. doi:10.1080/14623943.2010.490070

Yang, A., Chan, A., Ho, L. K., \& Tam, B. (2005). Does an open forum promote learning among students? A collaborative learning approach. Asian EFL Journal, 7(3), 88-97. 